\title{
Hospitalization for urinary tract infections in Japan, 2010-2015: a retrospective study using a national inpatient database
}

\author{
Akahito Sako ${ }^{1 *}$, Hideo Yasunaga ${ }^{2}$, Hiroki Matsui ${ }^{2}$, Kiyohide Fushimi ${ }^{3}$, Hidekatsu Yanai ${ }^{1}$, Yoshiaki Gu ${ }^{4}$ and \\ Norio Ohmagari ${ }^{5}$
}

\begin{abstract}
Background: Urinary tract infections (UTI) are common and can have severe consequences. However, there are few recent large-scale studies about them. We aimed to determine the incidence of hospitalization for UTI and to elucidate patient characteristics, clinical practice, and clinical outcomes by drawing on a Japanese nationwide database.

Methods: This was a retrospective observational study using a national database that covers half the acute care inpatients in Japan. Patients aged $\geq 15$ years who were hospitalized for UTI were eligible. We did not include patients with lower UTI such as cystitis. We investigated the annual number of patients hospitalized in Japan, those patients' characteristics, and risk factors for in-hospital mortality.

Results: We identified 232,396 eligible patients from 31 million records of discharge between April 2010 and March 2015. The average age was 73.5 years and $64.9 \%$ of patients were female. The estimated annual number of hospitalizations because of UTI was 106,508. The incidence was 6.8 per 10,000 for men and 12.4 for women. The median medical care cost was 4250 USD. In-hospital mortality was $4.5 \%$. Risk factors of poor survival included male sex, older age, lower bed capacity, non-academic hospital, admission in winter, higher Charlson Comorbidity Index score, low body mass index, coma on admission, ambulance use, disseminated intravascular coagulation, sepsis, renal failure, heart failure, cerebrovascular diseases, pneumonia, malignancies, use of anti-diabetic drugs, and use of corticosteroid or immunosuppressive drugs.
\end{abstract}

Conclusions: We found that older patients of both sexes accounted for a significant proportion of those hospitalized for UTI. The clinical and economic burden of UTI is considerable.

Keywords: Urinary tract infection, Pyelonephritis, Incidence, Mortality, Nationwide

\section{Background}

Urinary tract infections (UTI) such as acute pyelonephritis are the second most common type of infection requiring hospitalization after lower respiratory tract infections [1]. Previous studies have shown that the complications

\footnotetext{
*Correspondence: dsako@hospk.ncgm.go.jp

${ }^{1}$ Department of Internal Medicine, Kohnodai Hospital, National Center

for Global Health and Medicine, 1-7-1 Kohnodai, Ichikawa, Chiba

272-8516, Japan

Full list of author information is available at the end of the article
}

and mortality of acute pyelonephritis are associated with significant healthcare burdens [2]. The incidence of hospitalization for acute pyelonephritis in the USA was 11.7 per 10,000 for women and 2.4 for men in 1997 [3]. The direct and indirect costs of acute pyelonephritis were estimated as 2.14 billion USD in 2000 [2].

UTIs may progress to severe conditions such as sepsis, shock, and disseminated intravascular coagulation (DIC). The mortality of patients hospitalized for UTI or acute pyelonephritis is reportedly $1-9 \%[2,4-7]$. When 
accompanied by bacteremia, the mortality of acute pyelonephritis is $10-20 \%$ [8]. Risk factors for death are older age, immunosuppression, bedridden status, septic shock, DIC, disturbance of consciousness, and recent use of antibiotics [5, 8]. Early identification of patients with acute pyelonephritis at high risk of death may contribute to more effective treatment [8].

Nationwide studies that investigate the prevalence, patient characteristics, and clinical course of UTI are lacking. We therefore conducted a large-scale retrospective study using an administrative and clinical inpatient database to determine the incidence, patient characteristics, and clinical outcomes of hospitalization for UTI in Japanese acute care hospitals.

\section{Methods}

\section{Diagnosis procedure combination (DPC) database}

The participating hospitals voluntarily submit discharge abstract and administrative claims data to the DPC Research Group for clinical epidemiology research [9-12]. The validity of diagnoses recorded in the DPC database is generally high: the sensitivity and specificity of primary diagnoses have been reported to be $78.9 \%$ and $93.2 \%$, respectively [13]. As of 2012, the number of participating hospitals was 1098 , and the total number of beds 388,000 , accounting for $43 \%$ of all beds in acute care hospitals in Japan. In 2012, the number of hospital admissions in the database was 6.85 million, representing approximately $50 \%$ of all admissions from Japanese acute care hospitals.

\section{Patient selection and variables}

The DPC data contain a maximum of 12 diagnoses per patient and are listed according to International Classification of Diseases 10th Revision (ICD-10) codes and text data. They consist of four main diagnoses, four comorbidities on admission, and four complications during hospitalization. We retrospectively examined data on patients who had UTI-related ICD-10 codes (Additional file 1: Table S1) in the diagnoses for admission from the fiscal years 2010 to 2014. We also included patients who had DIC or sepsis related ICD-10 codes in the diagnosis for admission and had UTI in the comorbidities on admission because DIC and sepsis are common comorbidities of UTI, and reimbursements are higher for DIC and sepsis than for UTI. Although we did not review all diagnoses in the Japanese text data, we confirmed the diagnoses using text data if necessary. We did not include hospitalization for lower UTI such as cystitis, prostatitis, or urethritis because these conditions differ substantially from pyelonephritis or upper UTI. Additionally, we did not include nosocomial UTIs because we could not determine the date on which UTI developed after admission or the association of UTI and catheter indwelling. We excluded patients aged under 15 years and those who did not receive antibiotics on the day of admission. Thus, only patients aged $\geq 15$ years hospitalized for UTI alone or UTI with DIC or sepsis were eligible.

We used the following data: age; sex; body weight and height; discharge status; academic hospital or community hospital; number of beds; underlying diseases (Additional file 1: Table S1); pregnancy status; procedures and surgeries; medication use during hospitalization; medical costs. We divided body mass index (BMI) into the following five groups: underweight, $\mathrm{BMI}<18.50 \mathrm{~kg} / \mathrm{m}^{2}$; low-normal weight, 18.50-22.99; high-normal weight, 23.00-24.99; overweight, 25.00-29.99; and obese, $\geq 30.00$. Consciousness levels on admission and discharge were expressed as Japan Coma Scale (JCS) grades. We categorized these into four groups [14]: grade 0, alert; grade 1, drowsy, but awake without any stimuli; grade 2 , somnolent, but arousable with stimulation; and grade 3 , coma. We calculated the Charlson Comorbidity Index (CCI) scores as the burden of comorbidities $[15,16]$.

\section{Statistical analysis}

We estimated the number of hospitalizations for UTI (Y) in Japan by the following equation:

$$
\mathrm{Y}=\sum_{i=1}^{k} \frac{X i N i}{n i}
$$

where $N$ is the number of beds in all acute care hospitals in Japan, $n$ is the number of beds in DPC hospitals, and $X$ is the observed number of patients with UTI in DPC hospitals. We stratified hospitals by every 100 beds to adjust for the fact that DPC hospitals are skewed toward larger hospitals. We calculated the annual incidence of UTI by dividing the estimated number of patients with UTI (Y) by Japanese population in 2012 .

For univariate analysis, we used Student's $t$-test, the $\chi^{2}$ test, or Fisher's exact test as appropriate. We performed multivariable logistic regression analysis to identify the risk factors associated with in-hospital mortality. In the multivariable regression model, the independent variables included age, sex, and variables that were clinically relevant and significantly associated with in-hospital death by univariate analyses. We fitted multivariable logistic regression analyses for in-hospital mortality with generalized estimating equations to account for withinhospital clustering [17]. We calculated variance inflation factors for independent variables to avoid multicollinearity between the independent variables. We considered $P<0.05$ to denote statistical significance. All statistical 
analyses were performed by IBM SPSS Statistical package Version 25 (IBM, Armonk, NY, USA).

\section{Results}

Patient characteristics and incidence of hospitalization Among 31 million discharges from April 2010 to March 2015, 684,339 patients had any ICD-10 code for UTI among their 12 diagnoses. Finally, 232,396 patients were eligible (Fig. 1).

The patients' characteristics are shown in Table 1. Mean age was 73.4 years (Standard Deviation: 17.4). There were more female than male patients in all age groups. Young age (15-39 years) accounted for only 3.0\% of male but $8.8 \%$ of female patients. Overall, $1 \%$ of female patients in all age categories were pregnant and $11.1 \%$ of female patients aged 15-39 years. The average age of pregnant patients was 28.0 years and average week of pregnancy 23.4. The mean BMI was $21.9 \mathrm{~kg} / \mathrm{m}^{2}$ (SD 4.3) and average CCI score 0.9 (SD 1.3).

Patients aged $\geq 65$ years more frequently had underlying diseases related to UTI such as diabetes $(21.1 \%$ vs. $15.0 \%$ ), neurogenic bladder (5.9\% vs. $4.4 \%$ ), and prostate hyperplasia ( $19.2 \%$ vs. $9.9 \%$, male only) than younger patients. They also more frequently had complications of UTI such as sepsis (19.4 vs. $13.1 \%)$ and DIC (4.1\% vs. $2.6 \%)$.

Annual numbers of hospitalizations for UTI were 8.810.4 per 100 beds in hospitals with $<500$ beds and 5.0 7.6 in those with $\geq 500$ beds.
We observed clear seasonal changes every year (Fig. 2). UTIs were more prevalent (29.4\%) in summer (from June to August) followed by $27.6 \%$ in the fall, $22.0 \%$ in winter, and $21.1 \%$ in spring. We observed this seasonality in both sexes and in patients of all ages, even when categorized in 10-year intervals.

In 2012, the estimated numbers of hospitalizations for UTI in Japan were 35,969 for men and 70,539 for women. The estimated annual incidence of hospitalization for UTI was 6.8 per 10,000 for men and 12.4 per 10,000 for women. Incidences in male teens and men in their $50 \mathrm{~s}$ were $0.4-2.6$ per 10,000 , respectively, and those in female teens and women in their $50 \mathrm{~s}$ were $2.3-5.1$ per 10,000 , respectively. Incidences in patients over 60 were similar between men (5.7-91.6) and women (7.6-98.5) and much higher than younger patients (Fig. 3).

\section{Clinical courses and risk factors for in-hospital mortality}

Median length of hospitalization was 12 days (interquartile range: 11 days). Median medical cost was 4250 USD (interquartile range: 3960 USD; 1 USD $=100 \mathrm{JPY}$, during the study period, $1 \mathrm{USD}=80-120 \mathrm{JPY})$. Median length of stay and medical cost in patients $<65$ and $\geq 65$ years were 8 days and 13 days, respectively, and 3154 USD and 4630 USD, respectively.

Among the patients with obstructive and reflux uropathy, $34.2 \%$ had urolithiasis, $8.4 \%$ had urological malignancies, $6.3 \%$ had neuromuscular dysfunction of the bladder, and $5.7 \%$ had hyperplasia of the prostate. Among the patients with urolithiasis, $43.2 \%$ had

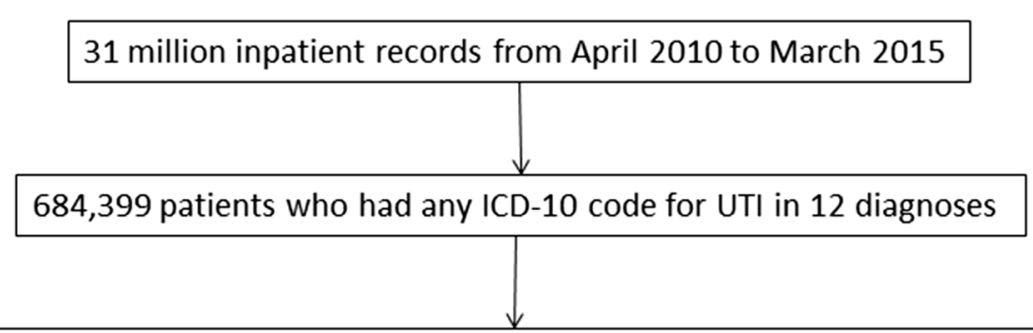

Age $\geq 15$ years: $91.6 \%$

Antibiotics for bacteria on first day: $64.5 \%$

Hospitalization for UTI

UTI in the diagnosis for admission: $38.7 \%$

Sepsis in the diagnosis for admission and UTI in the diagnosis of comorbidities at admission: $2.5 \%$

DIC in the diagnosis for admission and UTI in the diagnosis of comorbidities at admission: $0.3 \%$

232,396 eligible patients;

Patients aged $\geq 15$ years, who had antibiotics on first day, and hospitalized for UTI

Fig. 1 Study flow diagram showing selection of patients hospitalized for UTI 
Table.1 Patient characteristics $(n=232,396)$

\begin{tabular}{|c|c|c|}
\hline & $N$ & (\%) \\
\hline \multicolumn{3}{|l|}{ Sex } \\
\hline Female & 150,780 & 64.9 \\
\hline Pregnant & 1510 & 0.6 \\
\hline \multicolumn{3}{|l|}{ Age (years) } \\
\hline $15-19$ & 2068 & 0.9 \\
\hline $20-29$ & 6569 & 2.8 \\
\hline $30-39$ & 7034 & 3.0 \\
\hline $40-49$ & 9355 & 4.0 \\
\hline $50-59$ & 14,345 & 6.2 \\
\hline $60-69$ & 29,572 & 12.7 \\
\hline $70-79$ & 56,997 & 24.5 \\
\hline $80-89$ & 77,409 & 33.3 \\
\hline $90-99$ & 277,89 & 12.0 \\
\hline$\geq 100$ & 1258 & 0.5 \\
\hline Academic hospital & 22,831 & 9.8 \\
\hline Ambulance use & 72,946 & 31.4 \\
\hline \multicolumn{3}{|l|}{ Hospital bed capacity } \\
\hline 20-199 & 27,796 & 12.0 \\
\hline $200-299$ & 33,370 & 14.4 \\
\hline 300-399 & 54,321 & 23.4 \\
\hline $400-499$ & 38,716 & 16.7 \\
\hline $500-599$ & 33,301 & 14.3 \\
\hline $600-699$ & 19,634 & 8.4 \\
\hline$\geq 700$ & 23,512 & 10.1 \\
\hline Missing & 1746 & 0.8 \\
\hline \multicolumn{3}{|l|}{ Body mass index } \\
\hline$<18.5$ & 41,631 & 17.9 \\
\hline $18.5-22.9$ & 85,933 & 37.0 \\
\hline $23.0-24.9$ & 30,271 & 13.0 \\
\hline $25.0-29.9$ & 32,023 & 13.8 \\
\hline$\geq 30$ & 8405 & 3.6 \\
\hline Missing & 34,133 & 14.7 \\
\hline \multicolumn{3}{|c|}{ Charlson Comorbidity Index } \\
\hline 0 & 141,142 & 60.7 \\
\hline 1 & 22,954 & 9.9 \\
\hline 2 & 49,882 & 21.5 \\
\hline 3 & 7616 & 3.3 \\
\hline$\geq 4$ & 10,802 & 4.6 \\
\hline \multicolumn{3}{|c|}{ Japan Coma Scale grade on admission } \\
\hline Grade 0 (alert) & 177,491 & 76.4 \\
\hline Grade 1 (drowsy) & 39,135 & 16.8 \\
\hline Grade 2 (somnolent) & 11,452 & 4.9 \\
\hline Grade 3 (coma) & 4312 & 1.9 \\
\hline \multicolumn{3}{|l|}{ Underlying diseases } \\
\hline Cerebrovascular disease & 26,457 & 11.4 \\
\hline Dementia & 20,655 & 8.9 \\
\hline Pneumonia & 18,475 & 7.9 \\
\hline Sepsis & 41,711 & 17.9 \\
\hline Diabetes mellitus & 45,820 & 19.7 \\
\hline
\end{tabular}

Table.1 (continued)

\begin{tabular}{lrr}
\hline & \multicolumn{1}{c}{$\boldsymbol{N}$} & $\mathbf{( \% )}$ \\
\hline Ischemic heart disease & 14,857 & 6.4 \\
Disseminated intravascular coagulation & 8814 & 3.8 \\
Heart failure & 18,736 & 8.1 \\
Renal failure & 18,101 & 7.8 \\
Chronic respiratory disease & 10,115 & 4.4 \\
Chronic liver disease & 5624 & 2.4 \\
Schizophrenia & 4980 & 2.1 \\
Neuromuscular dysfunction of bladder & 13,012 & 5.6 \\
Hyperplasia of prostate & 14,276 & 6.1 \\
Urolithiasis & 24,758 & 10.7 \\
Malignancies & 28,682 & 12.3 \\
Urological malignancies & 12,828 & 5.5 \\
Obstructive and reflux uropathy & 28,624 & 12.3 \\
Therapeutic interventions & & \\
Mechanical ventilation & 3644 & 1.6 \\
Transurethral stenting & 19,177 & 8.3 \\
Percutaneous nephrostomy & 3781 & 1.6 \\
ESWL (Extracorporeal shock wave lithotripsy) & 2782 & 1.2 \\
Hemodialysis & 2881 & 1.2 \\
Intensive care unit admission & 3578 & 1.5 \\
\hline
\end{tabular}

transurethral stenting, 8.7\% had extracorporeal shock wave lithotripsy, and $5.6 \%$ had percutaneous nephrostomy. Among the patients with urological malignancies, $6.3 \%$ had transurethral stenting and $4.8 \%$ had percutaneous nephrostomy.

Antibiotics on admission and during hospitalization are shown in Table 2. Single antibiotics were given to 93.3\% of study patients on the first day. As for anti-DIC drugs during hospitalization, unfractionated heparin was given to $4.9 \%$ of study patients, thrombomodulinalfa to $2.1 \%$, and antithrombin III to $1.1 \%$. Any antiDIC drug, including heparin, was given to $8.3 \%$ (4.6\% excluding heparin). As to vasopressors during hospitalization, norepinephrine, dopamine, and dobutamine were given to $2.8 \%, 4.8 \%$, and $0.6 \%$ of study patients, respectively. Blood cultures were performed on $50.9 \%$ on admission.

The overall in-hospital mortality was $4.5 \%$. Crude inhospital mortality of patients aged $<65$ and $\geq 65$ years were $1.0 \%$ and $5.6 \%$. Results of multivariable logistic regression analysis for in-hospital mortality are shown in Table 3. The factors associated with poor survival were male sex, older age, lower bed capacity, non-academic hospital, admission in winter, higher CCI, low BMI, coma on admission, ambulance use, DIC, sepsis, renal failure, heart failure, cerebrovascular diseases, pneumonia, malignancies, anti-diabetic drugs including insulin, and corticosteroid or immunosuppressive drugs. 


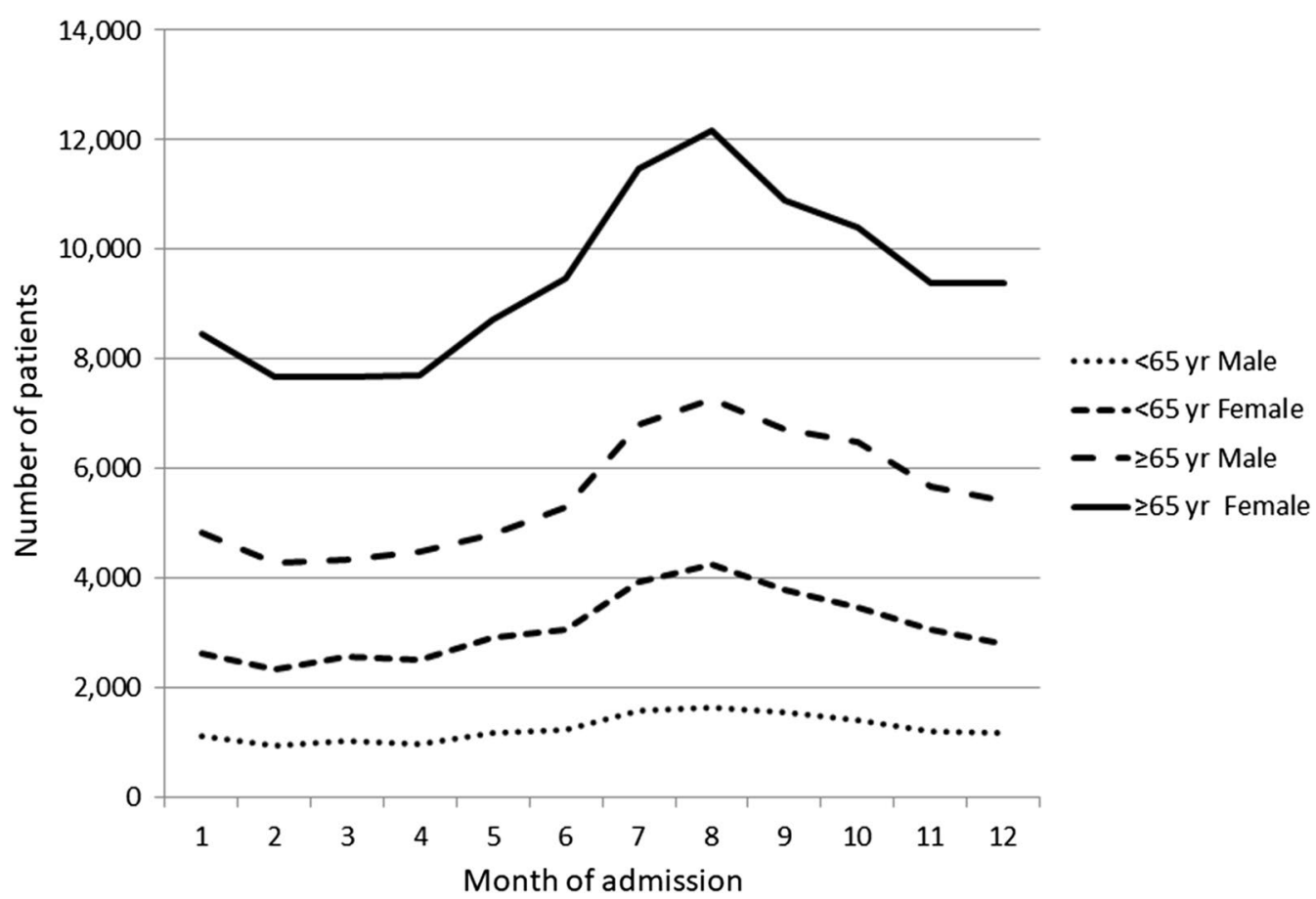

Fig. 2 Seasonal changes in number of hospitalizations for UTI stratified by age and sex

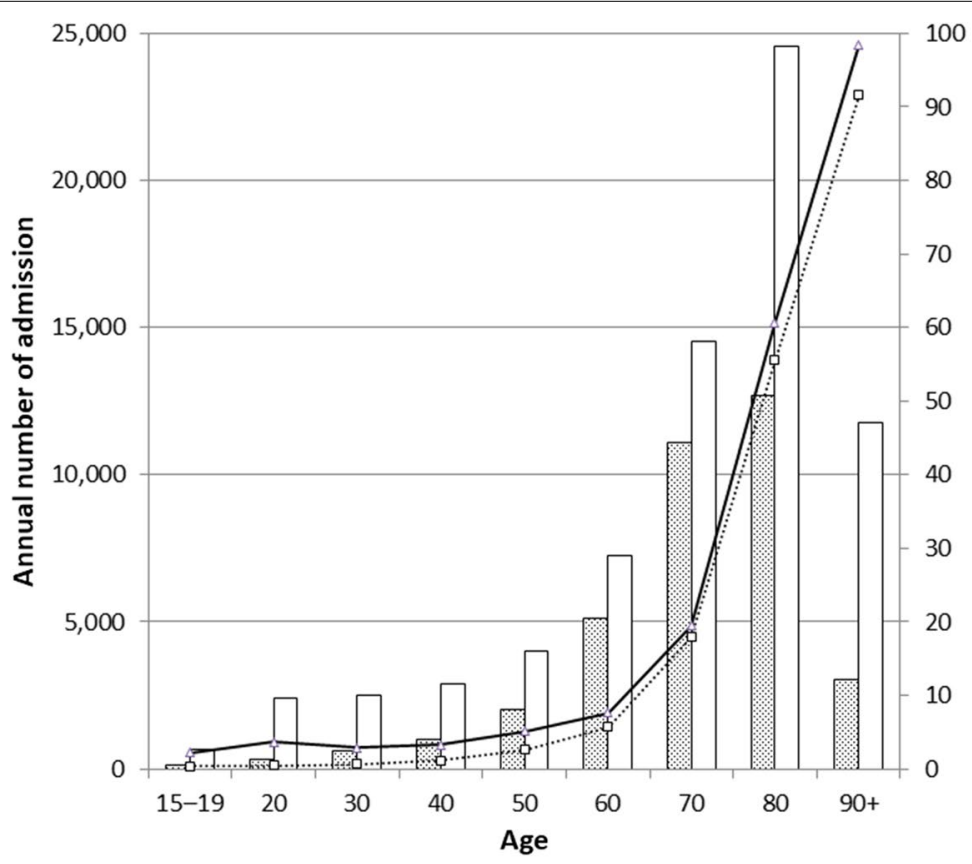

Fig. 3 Estimated annual number and incidence of admissions for UTI in Japan in 2012 stratified by sex

\section{Discussion}

This nationwide retrospective study involving 232,396 hospitalizations to acute care hospitals in Japan for UTI investigated both epidemiological and clinical data. Mean age was 73.5 years. Estimated number of hospitalizations for UTI in 2012 was 106,508. In-hospital mortality was $4.5 \%$, and we identified several risk factors for death. 
Table.2 Antibiotics on admission and during hospitalization $(n=232,396)$

\begin{tabular}{lrl}
\hline & 1st day (\%) & $\begin{array}{l}\text { During } \\
\text { hospitalization } \\
\text { (\%) }\end{array}$ \\
\hline Penicillins & 21.6 & 30.7 \\
First generation cephalosporins & 5.1 & 11.5 \\
Second generation cephalosporins & 18.5 & 24.0 \\
Third generation cephalosporins & 37.9 & 51.5 \\
Fourth generation cephalosporins & 4.4 & 6.1 \\
Carbapenems & 10.7 & 18.7 \\
Category of broadness of beta-lactams & & \\
Carbapenems & 10.7 & 18.7 \\
Antipseudomonal beta-lactams & 23.8 & 30.2 \\
Third generation cephalosporins with- & 31.8 & 45.0 \\
$\quad$ out antipseudomonal activity & & \\
Penicillins with beta-lactamase inhibitor & 7.9 & 11.5 \\
Other beta-lactams & 24.1 & 37.2 \\
Anti-MRSA drugs & 0.9 & 3.3 \\
Aminoglycosides & 1.6 & 3.3 \\
Fluoroquinolones & 4.5 & 30.2 \\
\hline
\end{tabular}

MRSA methicillin-resistant Staphylococcus aureus

There have been several nationwide studies on hospitalization for acute pyelonephritis [3, 18]. However, to the best of our knowledge, no such studies have been published since 2000. Additionally, our study includes more clinical information, such as patient characteristics, treatments, and outcomes.

A South Korean nationwide study reported an annual incidence of hospitalization for acute pyelonephritis in 1997-1999 of 1.2 per 10,000 population for men and 10.0 for women [18]. A population-based study in the USA from 1997 to 2001 reported annual rates of female outpatients and inpatients with acute pyelonephritis of 12-13 and 3-4 per 10,000 population, respectively, and 2-3 and 1-2 per 10,000 among male outpatients and inpatients, respectively [19]. We estimated annual incidences of hospitalization for UTI in Japan as 6.8 per 10,000 population for men and 12.4 for women. Although young women are at high risk of UTI, most patients hospitalized for UTI were older women and men, which would be partly attributable to the increasing aging in Japan. In our study, patients aged $\geq 65$ years more frequently had underlying diseases related to their UTIs.

Previous studies have shown that pregnancy is associated with a higher incidence of acute pyelonephritis or UTI and that these conditions increase the risk of preterm birth [20-23]. In 2006, 29,000 pregnant women were hospitalized in the USA for acute pyelonephritis [22]. Pregnant patients comprised from 18 to $31 \%$ of hospitalized patients with acute pyelonephritis and aged $<40$ years in Canada in 1990 [20]. In the current study, $11 \%$ of female patients aged 15-39 years were pregnant.

Diabetes is also a risk factor for acute pyelonephritis [20]. One-fifth of the patients in our study had diabetes, which is compatible with the previous study. Sodium-glucose co-transporter 2 (SGLT-2) inhibitors can increase the risk of UTI because of excretion of glucose into the urine [24]. Because SGLT-2 inhibitors were just introduced in Japan in 2014, the incidence of UTI in diabetic patients will increase as prescriptions for SGLT-2 inhibitors increase.

Several studies have shown that the incidence of acute pyelonephritis is highest in summer [18, 19, 22]. However, a study in the USA showed that both sexes are more likely to be hospitalized for acute pyelonephritis in winter and that crude mortality in male patients is highest in winter and spring [21]. We found seasonal variations in incidence and a peak in summer in both sexes and all age categories. Although the reasons for seasonal fluctuations are unknown, possibilities include changes in behavior, environmental, and microbial factors [18]. In our study, winter was an independent risk factor for death. A previous USA study showed death from all natural causes increased in winter [25], which supports our results.

A Korean nationwide study in 1997-99 showed an average duration of hospitalization for acute pyelonephritis of 7.9 days. The total annual medical cost for it accounted for $0.2 \%$ of national medical costs [18]. Nearly 2 billion USD for community-acquired and nosocomial UTIs in the USA is a significant health economic burden [26]. We found that mean medical cost of hospitalization for UTIs was 6,230 USD and the estimated annual cost in Japan 663 million USD. Taking into account the medical cost of nosocomial UTIs and outpatient care, and indirect costs such as absenteeism, the economic burden of UTIs is significant. Aging has a major impact on disease burden because of the associated multiple comorbidities. We showed patients aged $\geq 65$ years more frequently had severe complications of UTI, were hospitalized for longer, and accumulated greater cost.

Mortality varies between studies because of differences in clinical settings, definitions of UTI, comorbidities, and severity. In a retrospective study of acute pyelonephritis in Greece showed septic shock occurred in $20 \%$ of patients and the mortality was $13.3 \%$ [8]. In a Japanese multi-center study of obstructive pyelonephritis caused by urolithiasis, $12 \%$ of the patients had DIC, $15 \%$ needed vasopressors, $67 \%$ underwent urinary drainage, and the overall mortality was $2.3 \%$ [5]. Prospective observational study of complicated pyelonephritis in Spain showed the mortality was $6.5 \%$ [6]. Mortality in our study was $4.5 \%$. Our patients were not limited to complicated UTI nor 
Table.3 Results of logistic regression analysis for in-hospital mortality

\begin{tabular}{|c|c|c|c|c|c|c|}
\hline \multirow{2}{*}{ Sex } & \multirow[t]{2}{*}{ Crude mortality (\%) } & \multirow[t]{2}{*}{ Adjusted odds ratio } & \multicolumn{3}{|c|}{$95 \%$ confidence interval } & \multirow[t]{2}{*}{$P$} \\
\hline & & & & & & \\
\hline Female & 4.3 & 0.88 & 0.83 & - & 0.93 & $<0.001$ \\
\hline Male & 5.0 & 1.00 & Ref. & & & \\
\hline \multicolumn{7}{|l|}{ Age (years) } \\
\hline$\geq 90$ & 9.8 & 16.51 & 10.85 & - & 25.14 & $<0.001$ \\
\hline $80-89$ & 6.2 & 10.20 & 6.72 & - & 15.50 & $<0.001$ \\
\hline 70-79 & 3.5 & 6.32 & 4.16 & - & 9.59 & $<0.001$ \\
\hline $60-69$ & 2.2 & 4.47 & 2.93 & - & 6.82 & $<0.001$ \\
\hline $50-59$ & 1.3 & 3.77 & 2.44 & - & 5.83 & $<0.001$ \\
\hline $40-49$ & 0.6 & 2.47 & 1.50 & - & 4.06 & $<0.001$ \\
\hline$\leq 39$ & 0.2 & 1.00 & Ref. & & & \\
\hline \multicolumn{7}{|l|}{ Hospital bed capacity } \\
\hline$\geq 700$ & 3.6 & 0.78 & 0.65 & - & 0.94 & 0.008 \\
\hline $600-699$ & 4.3 & 0.79 & 0.66 & - & 0.94 & 0.008 \\
\hline 500-599 & 4.3 & 0.79 & 0.68 & - & 0.92 & 0.002 \\
\hline 400-499 & 4.4 & 0.82 & 0.71 & - & 0.95 & 0.010 \\
\hline 300-399 & 4.6 & 0.90 & 0.79 & - & 1.03 & 0.123 \\
\hline $200-299$ & 5.2 & 1.01 & 0.87 & - & 1.16 & 0.947 \\
\hline$\leq 199$ & 5.1 & 1.00 & Ref. & & & \\
\hline \multicolumn{7}{|l|}{ Type of hospital } \\
\hline Academic & 3.0 & 0.73 & 0.64 & - & 0.84 & $<0.001$ \\
\hline Community & 4.7 & 1.00 & Ref. & & & \\
\hline \multicolumn{7}{|l|}{ Season of admission } \\
\hline Winter & 5.3 & 1.11 & 1.04 & - & 1.20 & 0.004 \\
\hline Autumn & 4.4 & 0.99 & 0.92 & - & 1.06 & 0.705 \\
\hline Summer & 4.0 & 0.89 & 0.83 & - & 0.96 & 0.002 \\
\hline Spring & 4.6 & 1.00 & Ref. & & & \\
\hline \multicolumn{7}{|c|}{ Charlson Comorbidity Index } \\
\hline$\geq 4$ & 12.6 & 1.83 & 1.62 & - & 2.06 & $<0.001$ \\
\hline 3 & 7.6 & 0.89 & 0.78 & - & 1.02 & 0.096 \\
\hline 2 & 6.2 & 1.06 & 0.98 & - & 1.16 & 0.161 \\
\hline 1 & 3.9 & 0.94 & 0.85 & - & 1.03 & 0.184 \\
\hline 0 & 3.2 & 1.00 & Ref. & & & \\
\hline \multicolumn{7}{|c|}{ Body mass index $\left(\mathrm{kg} / \mathrm{m}^{2}\right)$} \\
\hline$\geq 30.0$ & 1.7 & 0.75 & 0.63 & - & 0.88 & 0.001 \\
\hline $25.0-29.9$ & 2.1 & 0.71 & 0.65 & - & 0.78 & $<0.001$ \\
\hline $23.0-24.9$ & 2.5 & 0.74 & 0.68 & - & 0.81 & $<0.001$ \\
\hline $18.5-22.9$ & 3.7 & 1.00 & Ref. & & & \\
\hline$<18.5$ & 7.5 & 1.67 & 1.58 & - & 1.78 & $<0.001$ \\
\hline \multicolumn{7}{|c|}{ Japan Coma Scale grade on admission } \\
\hline Grade 3 (coma) & 26.3 & 4.51 & 4.00 & - & 5.09 & $<0.001$ \\
\hline Grade 2 (somnolent) & 13.4 & 2.35 & 2.13 & - & 2.59 & $<0.001$ \\
\hline Grade 1 (drowsy) & 6.8 & 1.46 & 1.35 & - & 1.57 & $<0.001$ \\
\hline Grade 0 (alert) & 2.9 & 1.00 & Ref. & & & \\
\hline \multicolumn{7}{|l|}{ Ambulance use } \\
\hline Yes & 6.8 & 1.12 & 1.05 & - & 1.18 & $<0.001$ \\
\hline No & 3.5 & 1.00 & Ref. & & & \\
\hline \multicolumn{7}{|c|}{ Disseminated intravascular coagulation } \\
\hline Yes & 20.4 & 2.92 & 2.66 & - & 3.20 & $<0.001$ \\
\hline
\end{tabular}


Table.3 (continued)

\begin{tabular}{|c|c|c|c|c|c|c|}
\hline & Crude mortality (\%) & Adjusted odds ratio & \multicolumn{3}{|c|}{$95 \%$ confidence interval } & $P$ \\
\hline No & 3.9 & 1.00 & Ref. & & & \\
\hline \multicolumn{7}{|c|}{ Sepsis } \\
\hline Yes & 11.3 & 2.35 & 2.19 & - & 2.53 & $<0.001$ \\
\hline No & 3.1 & 1.00 & Ref. & & & \\
\hline \multicolumn{7}{|c|}{ Renal failure } \\
\hline Yes & 10.6 & 2.29 & 2.12 & - & 2.47 & $<0.001$ \\
\hline No & 4.0 & 1.00 & Ref. & & & \\
\hline \multicolumn{7}{|c|}{ Heart failure } \\
\hline Yes & 11.3 & 1.88 & 1.71 & - & 2.06 & $<0.001$ \\
\hline No & 3.9 & 1.00 & Ref. & & & \\
\hline \multicolumn{7}{|c|}{ Cerebrovascular disease } \\
\hline Yes & 6.5 & 1.20 & 1.11 & - & 1.29 & $<0.001$ \\
\hline No & 4.3 & 1.00 & Ref. & & & \\
\hline \multicolumn{7}{|c|}{ Pneumonia } \\
\hline Yes & 16.4 & 3.35 & 3.13 & - & 3.60 & $<0.001$ \\
\hline No & 3.5 & 1.00 & Ref. & & & \\
\hline \multicolumn{7}{|c|}{ Malignancies } \\
\hline Yes & 8.8 & 3.17 & 2.89 & - & 3.48 & $<0.001$ \\
\hline No & 3.9 & 1.00 & Ref. & & & \\
\hline \multicolumn{7}{|c|}{ Use of anti-diabetic drugs } \\
\hline Yes & 6.7 & 1.47 & 1.38 & - & 1.56 & $<0.001$ \\
\hline No & 4.1 & 1.00 & Ref. & & & \\
\hline \multicolumn{7}{|c|}{ Use of corticosteroid or immunosuppressive drugs } \\
\hline Yes & 11.6 & 2.73 & 2.56 & - & 2.92 & $<0.001$ \\
\hline No & 3.8 & 1.00 & Ref. & & & \\
\hline
\end{tabular}

All of the above variables were used for calculation of the adjusted odds ratios

tertiary care hospitals; thus, rates of septic shock and DIC were not as high as those in other studies.

We identified the additional risk factors of male sex, low BMI, and use of anti-diabetic drugs to those identified in previous studies. Several studies have shown that low BMI and being underweight are risk factors for death from pneumonia $[27,28]$ and another study showed lower mortality in obese patients with pneumonia [29]. Few studies have examined the association between BMI and mortality from UTI and none have identified a significant association [29]. Our study is the first to show a significant impact of underweight on mortality from UTI.

This study has several limitations. First, the DPC database does not contain some clinical information, including vital signs and laboratory and imaging data. We could not confirm the diagnosis of UTI based on symptoms, pyuria, and positive urine culture. We could not confirm obstruction of the urinary tract using imaging data from CT or ultrasonography. Although pyelonephritis and tubulointerstitial nephritis had the same ICD-10 codes, we were able to exclude tubulointerstitial nephritis using data on antibiotic use on admission and diagnoses in the
Japanese text data. Because we selected eligible patients on the basis of diagnoses on admission, we may have overlooked patients with UTI and severe concurrent diseases other than DIC or sepsis on admission, such as renal failure and disturbance of consciousness, thus possibly underestimating the numbers of hospitalizations for UTI. Second, we intended to investigate patients with upper UTI or pyelonephritis; however, many patients had unspecified UTI diagnoses. We think most of these patients had upper UTI or pyelonephritis because it is common to use the diagnosis of UTI for pyelonephritis in Japan, and patients with cystitis rarely need hospitalization. Third, the DPC database is limited to acute care hospitals, and participating hospitals are skewed toward large academic hospitals. To adjust for this, we stratified hospitals by bed capacity. Fourth, the DPC database only contains inpatient information and is not linked with other databases such as outpatient records and vital statistics. Thus, we were unable to investigate antibiotics and urinary catheter before admission and survival after discharge, limiting our findings to short-term clinical course and in-hospital mortality. Fifth, because length of 
hospital stay of acute care in Japan was more than twice as long as other developed countries [30], it is difficult to compare length of hospitalization with studies in other countries. Despite these limitations, in this nationwide study we have determined the estimated annual incidence, patient characteristics, clinical practice, and inhospital mortality of hospitalizations for UTI in Japan based on recent clinical and epidemiological data.

\section{Conclusions}

Although young women are well known to be at relatively high risk of UTI, we found that older patients of both sexes account for a significant proportion of those hospitalized for UTI. The clinical and economic burden of UTI is considerable. In-hospital mortality is relatively low; however, clinician should carefully manage comorbidities and risk factors.

\author{
Abbreviations \\ UTI: Urinary tract infections; DIC: Disseminated intravascular coagulation; \\ DPC: Diagnosis procedure combination; ICD-10: International Classification \\ of Diseases 10th Revision; BMI: Body mass index; JCS: Japan Coma Scale; CCI: \\ Charlson Comorbidity Index; SD: Standard deviation; SGLT-2: Sodium-glucose \\ co-transporter 2; MRSA: Methicillin-resistant Staphylococcus aureus; ESWL: \\ Extracorporeal shock wave lithotripsy.
}

\section{Supplementary Information}

The online version contains supplementary material available at https://doi. org/10.1186/s12879-021-06735-y.

Additional file 1: Table S1. ICD-10 codes for UTI and underlying diseases.

\section{Acknowledgements}

Not applicable.

\section{Authors' contributions}

AS and H.Yasunaga (HY1) are the guarantors of this work, had full access to all data in the study, and take responsibility for the integrity of the data and the accuracy of the data analysis. Study concept and design: AS, HY1, NO. Acquisition, analysis, or interpretation of data: AS, HY1, HM, YG, NO. Drafting of the manuscript: AS, HY1. Critical revision of the manuscript for important intellectual content: HY1, H.Yanai (HY2), YG, NO. Statistical analysis: AS, HY1. Administrative, technical, or material support: HY1, HM, KF, HY2. Study supervision: HY1, HY2, YG, NO. All authors read and approved the final manuscript.

\section{Funding}

This work was supported by Grants for Research on Policy Planning and Evaluation from the Ministry of Health, Labour and Welfare, Japan (Grant Numbers: H30-Policy-Designated-004 and H29-Policy-General-004), and a grant from the National Center for Global Health and Medicine (Grant Number: 20A-3001). The funding institutions had no role in the design and conduct of the study, collection, management, analysis, and interpretation of the data, preparation, review, or approval of the manuscript, or decision to submit the manuscript for publication.

\section{Availability of data and materials}

The datasets used and/or analysed during the current study are not publicly available for ethical reasons as the data are patient data. The datasets are available from the corresponding author on reasonable request, pending ethical approval.

\section{Declarations}

\section{Ethics approval and consent to participate}

The requirement for informed consent was waived because this study was a retrospective study of administrative data and data was anonymised before its use. The Institutional Review Board at The University of Tokyo approved the study.

\section{Consent for publication}

Not applicable.

\section{Competing interests}

The authors have no conflicts of interest to disclose.

\section{Author details}

${ }^{1}$ Department of Internal Medicine, Kohnodai Hospital, National Center for Global Health and Medicine, 1-7-1 Kohnodai, Ichikawa, Chiba 272-8516, Japan. ${ }^{2}$ Department of Clinical Epidemiology and Health Economics, School of Public Health, Graduate School of Medicine, The University of Tokyo, 7-3-1 Hongo, Bunkyo-ku, Tokyo, Japan. ${ }^{3}$ Department of Health Informatics and Policy, Tokyo Medical and Dental University Graduate School of Medicine, 1-5-45 Yushima, Bunkyo-ku, Tokyo, Japan. ${ }^{4}$ Department of Infectious Diseases, Tokyo Medical and Dental University Graduate School of Medical and Dental Sciences, 1-5-45 Yushima, Bunkyo-ku, Tokyo, Japan. ${ }^{5}$ Disease Control and Prevention Center, Center Hospital, National Center for Global Health and Medicine, 1-21-1 Toyama, Shinjuku-ku, Tokyo, Japan.

Received: 5 March 2020 Accepted: 24 September 2021

Published online: 09 October 2021

\section{References}

1. Christensen KL, Holman RC, Steiner CA, Sejvar JJ, Stoll BJ, Schonberger LB. Infectious disease hospitalizations in the United States. Clin Infect Dis. 2009;49(7):1025-35.

2. Brown P, Ki M, Foxman B. Acute pyelonephritis among adults: cost of illness and considerations for the economic evaluation of therapy. Pharmacoeconomics. 2005;23(11):1123-42.

3. Foxman B, Klemstine KL, Brown PD. Acute pyelonephritis in US hospitals in 1997: hospitalization and in-hospital mortality. Ann Epidemiol. 2003;13(2):144-50.

4. Kim Y, Wie SH, Chang UI, Kim J, Ki M, Cho YK, et al. Comparison of the clinical characteristics of diabetic and non-diabetic women with community-acquired acute pyelonephritis: a multicenter study. J Infect. 2014;69(3):244-51.

5. Hamasuna R, Takahashi S, Nagae H, Kubo T, Yamamoto S, Arakawa S, et al. Obstructive pyelonephritis as a result of urolithiasis in Japan: diagnosis, treatment and prognosis. Int J Urol. 2015;22(3):294-300.

6. Buonaiuto VA, Marquez I, De Toro I, Joya C, Ruiz-Mesa JD, Seara R, et al. Clinical and epidemiological features and prognosis of complicated pyelonephritis: a prospective observational single hospital-based study. BMC Infect Dis. 2014;14:639.

7. Eliakim-Raz N, Babitch T, Shaw E, Addy I, Wiegand I, Vank C, et al. Risk factors for treatment failure and mortality among hospitalised patients with complicated urinary tract infection: a multicentre retrospective cohort study, RESCUING Study Group. Clin Infect Dis. 2019;68(1):29-36.

8. Efstathiou SP, Pefanis AV, Tsioulos DI, Zacharos ID, Tsiakou AG, Mitromaras $\mathrm{AG}$, et al. Acute pyelonephritis in adults: prediction of mortality and failure of treatment. Arch Intern Med. 2003;163(10):1206-12.

9. Sako A, Yasunaga $H$, Horiguchi H, Fushimi K, Yanai H, Uemura N. Prevalence and in-hospital mortality of gastrostomy and jejunostomy in Japan: a retrospective study with a national administrative database. Gastrointest Endosc. 2014;80(1):88-96.

10. Tagami T, Matsui $H$, Fushimi $K$, Yasunaga H. Prophylactic antibiotics may improve outcome in patients with severe burns requiring mechanical ventilation: propensity score analysis of a Japanese nationwide database. Clin Infect Dis. 2016;62(1):60-6. 
11. Yamana H, Matsui H, Tagami T, Hirashima J, Fushimi K, Yasunaga H. De-escalation versus continuation of empirical antimicrobial therapy in community-acquired pneumonia. J Infect. 2016;73(4):314-25.

12. Shigemi D, Matsui H, Fushimi K, Yasunaga $H$. Therapeutic impact of initial treatment for Chlamydia trachomatis among patients with pelvic inflammatory disease: a retrospective cohort study using a national inpatient database in Japan. Clin Infect Dis. 2019;69(2):316-22.

13. Yamana H, Moriwaki M, Horiguchi $H$, Kodan M, Fushimi K, Yasunaga $H$. Validity of diagnoses, procedures, and laboratory data in Japanese administrative data. J Epidemiol. 2017;27:476-82.

14. Shigematsu $K$, Nakano $H$, Watanabe $Y$. The eye response test alone is sufficient to predict stroke outcome-reintroduction of Japan Coma Scale: a cohort study. BMJ Open. 2013;3(4):e002376.

15. Quan H, Sundararajan V, Halfon P, Fong A, Burnand B, Luthi JC, et al. Coding algorithms for defining comorbidities in ICD-9-CM and ICD-10 administrative data. Med Care. 2005;43(11):1130-9.

16. Charlson ME, Pompei P, Ales KL, MacKenzie CR. A new method of classifying prognostic comorbidity in longitudinal studies: development and validation. J Chronic Dis. 1987;40(5):373-83.

17. Hubbard AE, Ahern J, Fleischer NL, Van der Laan M, Lippman SA, Jewell $\mathrm{N}$, et al. To GEE or not to GEE: comparing population average and mixed models for estimating the associations between neighborhood risk factors and health. Epidemiology. 2010;21(4):467-74.

18. Ki M, Park T, Choi B, Foxman B. The epidemiology of acute pyelonephritis in South Korea, 1997-1999. Am J Epidemiol. 2004;160(10):985-93.

19. Czaja CA, Scholes D, Hooton TM, Stamm WE. Population-based epidemiologic analysis of acute pyelonephritis. Clin Infect Dis. 2007;45(3):273-80.

20. Nicolle LE, Friesen D, Harding GK, Roos LL. Hospitalization for acute pyelonephritis in Manitoba, Canada, during the period from 1989 to 1992; impact of diabetes, pregnancy, and aboriginal origin. Clin Infect Dis. 1996:22(6):1051-6.

21. Foxman B, Klemstine KL, Brown PD. Acute pyelonephritis in US hospitals in 1997: hospitalization and in-hospital mortality. Ann Epidemiol. 2003;13(2):144-50.
22. Jolley JA, Kim S, Wing DA. Acute pyelonephritis and associated complications during pregnancy in 2006 in US hospitals. J Matern Fetal Neonatal Med. 2012;25(12):2494-8

23. Delzell JE, Lefevre ML. Urinary tract infections during pregnancy. Am Fam Physician. 2000;61(3):713-21.

24. Vasilakou D, Karagiannis T, Athanasiadou E, Mainou M, Liakos A, Bekiari E, et al. Sodium-glucose cotransporter 2 inhibitors for type 2 diabetes: a systematic review and meta-analysis. Ann Intern Med. 2013;159(4):262-74.

25. Phillips D, Barker GE, Brewer KM. Christmas and New Year as risk factors for death. Soc Sci Med. 2010;71(8):1463-71.

26. Foxman B. Epidemiology of urinary tract infections: incidence, morbidity, and economic costs. Am J Med. 2002;113(Suppl 1A):5S-13S.

27. Inoue Y, Koizumi A, Wada Y, Iso H, Watanabe Y, Date C, et al. Risk and protective factors related to mortality from pneumonia among middle aged and elderly community residents: the JACC Study. J Epidemiol. 2007;17(6):194-202.

28. LaCroix AZ, Lipson S, Miles TP, White L. Prospective study of pneumonia hospitalizations and mortality of U.S. older people: the role of chronic conditions, health behaviors, and nutritional status. Public Health Rep. 1989:104(4):350-60.

29. Atamna A, Elis A, Gilady E, Gitter-Azulay L, Bishara J. How obesity impacts outcomes of infectious diseases. Eur J Clin Microbiol Infect Dis. 2017;36(3):585-91.

30. Organisation for Economic Co-operation and Development. OECD Health Statistics. Health care utilisation. Length of hospital stay. https:// data.oecd.org/healthcare/length-of-hospital-stay.htm [accessed 5 March 2020].

\section{Publisher's Note}

Springer Nature remains neutral with regard to jurisdictional claims in published maps and institutional affiliations.
Ready to submit your research? Choose BMC and benefit from:

- fast, convenient online submission

- thorough peer review by experienced researchers in your field

- rapid publication on acceptance

- support for research data, including large and complex data types

- gold Open Access which fosters wider collaboration and increased citations

- maximum visibility for your research: over $100 \mathrm{M}$ website views per year

At BMC, research is always in progress.

Learn more biomedcentral.com/submissions 